Section Editors

David C. Spencer, MD

Steven Karceski, MD

\title{
How migraines affect cognitive function
}

Steven C. Karceski, MD
In the article "How migraines affect cognitive function: Findings from the Baltimore ECA," Dr. Kalaydjian and her colleagues report new information about people who have migraine headaches. Although they discuss many different topics, they focus their attention on how migraine affects a person's thinking. There is still much to learn about headaches and migraines. Older studies suggested that people with migraines, also called migraineurs, might have more problems with thinking. Dr. Kalaydjian's study showed the exact opposite: Migraineurs had fewer problems.

\section{RETROSPECTIVE VS PROSPECTIVE STUDIES}

There are many ways to study an illness. Some studies are retrospective. This means that the authors looked through their charts to find people who had a specific diagnosis like migraine or stroke. Once they collected the charts, they looked through the charts to see what kinds of problems the group shared. There are many problems to this type of study.

For instance, many people with migraine take pain medications. In a retrospective study, the use of pain medications would be something shared by a large number of migraineurs. We might think that the answer made perfect sense. A person in pain would take a pain medicine.

However, this is not the only possible conclusion. Remember that the retrospective study shows only those things that a group of people have in common. Suppose the medication caused the headaches? If true, we might decide that people with migraine should avoid this kind of medication.

Dr. Kalaydjian used a prospective study to avoid these problems. A prospective study assembles the group of people first. The study follows all of the people for a set period of time. Because of this, prospective studies can show both the cause and the consequences of an illness. In other words, prospective studies usually give more accurate, less confusing answers.

Dr. Kalaydjian studied a large number of people. She also followed them over a long time (average was 12 years). Within Dr. Kalaydjian's total group, there was a smaller number who had headaches. Her study compared the headache group with those who do not have headache.

WHAT HAVE PREVIOUS STUDIES REPORTED? In the past, most studies were retrospective. Not only this, but most studies looked at a small number of people. These studies showed that migraines go along with depression, tremors, seizures, and stroke. They also showed that migraineurs have more problems with thinking clearly.
The problem is that we do not know how these are associated. For instance, did migraine cause stroke? Maybe people who have strokes are more likely to have headaches? Do migraines cause seizures? Or do seizures cause headaches? As with many retrospective studies, the answers are unclear.

Dr. Kalaydjian decided to clear up this confusion. For instance, if migraines cause strokes, we might expect that with more migraines, there should be more strokes. Over time, a person with migraine would have more and more trouble thinking clearly because of a slowly increasing number of strokes. In other words, the no-headache group might show some changes over time due to age. The migraine group would be expected to do worse.

Dr. Kalaydjian found the opposite answer. Instead of having more problems with thinking, the migraine group had fewer. Because the answer was unexpected, Dr. Kalaydjian went back and looked at the result in several ways.

First, she looked at the difference in the ages of the two groups. The people in the migraine group were 5 years younger than the ones in the no-headache group. As we get older, we have more troubles with thinking. Maybe the reason the no-headache group did worse was that they were older. By making extra calculations, she corrected for this difference. The answer was the same. The migraine groups still did better over time than the no-migraine group.

Second, there was a difference in the number of people who had depression. The migraine group had depression three times more than the no-headache group. Many studies show that depression causes memory problems. We would expect the people who had depression to also have more problems with thinking and memory. If the migraine group had depression more, why did they do better?

The answers to these questions remain unclear. Maybe the headache group lived "healthier." Poor sleep can cause problems with concentration. Knowing that poor sleep also can cause headaches, the headache group may have slept better. As a result, they also had fewer problems with attention or concentration.

Perhaps the people with headaches were taking medicines that prevented other problems. For instance, blood pressure medication often helps to treat migraines. Many of the migraineurs were on these medications. They should have had lower blood pressure and fewer strokes. Maybe this is why they fared better than the no-migraine group. Only more study will answer this. 
WHAT IS MIGRAINE? This is a difficult question to answer. Migraine is defined as five or more episodes of head pain in a lifetime. Most people report that migraine pain is very severe. It is often throbbing. Most of the time, the pain affects only one side of the head. The pain lasts several hours. It causes sensitivity to both light and noise.

TREATMENT OF MIGRAINE Migraines can have specific triggers. Avoiding the triggers is one treatment for migraine. Chocolate, aged cheeses, strong smells, or loud noises can cause migraines. For some people, exercise will cause a headache. In some, caffeine causes headaches. In others, caffeine helps to stop the migraine. This is the reason why Excedrin helps so many people with migraine. It contains aspirin, a pain medication. It also has caffeine.

Pain medicines are another treatment. There are many kinds of pain medicines. Although they all work, it can sometimes be hard to know which one will work for a specific person. In other words, what works for one may not work for another migraineur. This can be very frustrating. People may need to try several different medicines before finding the one that works best for them.

Pain medicines are broken down into two categories. The first are abortive medicines. These are the ones that a person takes when the headache happens. Often, these medicines work best if they are taken just as the headache first starts. The sooner a person takes them, the better they work.

The second kind of migraine medicine is prophylaxis. These medicines work by preventing headaches. They do not work if they are taken when the headache starts. Instead, a person takes this kind of medicine every day, even on days where there is no headache.

Most people need both kinds. One medicine keeps the headaches from happening often. The second one stops a headache in progress.

\section{FOR MORE INFORMATION}

The Brain Matters

http://www.thebrainmatters.org/

The American Headache Society

http://www.americanheadachesociety.org/ 


\title{
Neurology
}

\author{
How migraines affect cognitive function \\ Steven C. Karceski \\ Neurology 2007;68;E23-E24 \\ DOI 10.1212/01.wnl.0000263654.04363.d3
}

This information is current as of April 23, 2007

Updated Information \& Services

Permissions \& Licensing

Reprints including high resolution figures, can be found at: http://n.neurology.org/content/68/17/E23.full

Information about reproducing this article in parts (figures,tables) or in its entirety can be found online at:

http://www.neurology.org/about/about_the_journal\#permissions

Information about ordering reprints can be found online:

http://n.neurology.org/subscribers/advertise

Neurology ${ }^{\circledR}$ is the official journal of the American Academy of Neurology. Published continuously since 1951, it is now a weekly with 48 issues per year. Copyright . All rights reserved. Print ISSN: 0028-3878. Online ISSN: 1526-632X.

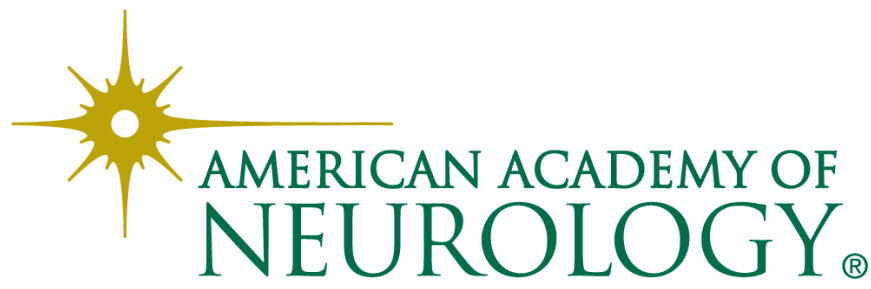

